\title{
The Essence of Eddie: A Reflection of the Interplay Between Art, Relationships, and Emotion
}

\author{
Maryam Soltani
}

Received: 22 August 2014 / Accepted: 15 September 2014/Published online: 12 November 2014

(C) Academic Psychiatry 2014

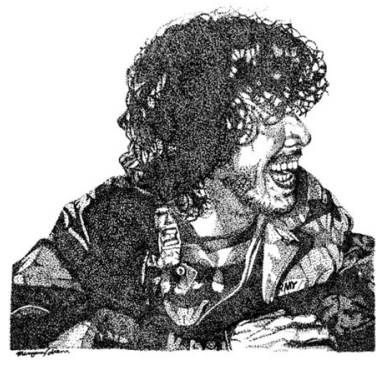

Art as the recreation of emotional experience in lives and in relationships brings us together. The artist concentrates, focusing on the smallest details, absorbed in creation form and feeling, emotional expression in its subtlest nuances. Facial expressions can teach us about the complexities of emotional life; how emotion is revealed through lines and curves, depressions, elevations, and shading: the contours of life and its shadow experiences. Each line leads to an understanding of a person or experience.

Through imagery we imagine what people have gone through: What have they struggled with? What makes them laugh? Do they understand the meaning of the inscriptions on their faces? A drawing is not finished until it is "alive": Will the image "speak" to others, can it impart humor, excite thought or conjure a feeling, inspire awareness of suffering and hope for deliverance? In this way, drawing, and art in general, are vital links between people, affirming our connection to each other: our interdependency.

"The Essence of Eddie" embodies the interdependency between people and the interplay of forces within a person; it is an image of a young man striving to make ends meet. Eddie, a talented musician and poet, aspires to establish a place in this world. His broad smile betrays both the miseries and the joys of his life. Like moments in a life time, spread across the matrix of being, thousands of tiny dots compose the greater image of Eddie; molecules of feeling, thinking and experiencing, a collective force so vital as to emotionally nourish and sustain an artist though he may not have eaten for days, while he renders experience into new musical and poetic forms. Eddie makes the dots swirl until they rest momentarily on the day's theme, and then light off again to assume new forms somewhere else in the matrix.

It has been said, "Art keeps ideas alive." In medicine we strive to keep people alive. I believe that it is art in medicine that keeps people alive. Healing resides in the original ideas of the physician, an artistic blend of science and intuition, heart and mind, and in the ability to convey these ideas through interaction and instrumentation within a special human relationship of trust and hope. This relationship is a broader matrix of pointillism comprised of two individuals engaged in a process of understanding and healing. Each one of us, doctor and patient, is "Eddie." The physician must be able to see into each individual and appreciate the singular artistry within in order to conjure and inspire the inner forces of renewal and healing. Each patient, then, is also the physician's music and poetry. And, who knows what other healing the doctor's art may inspire in the collective matrices of our interdependent lives, after it has breathed new life into one person?

Acknowledgments The author would like to thank Dr. Greg Gurnick for his assistance with and feedback regarding the written work.
M. Soltani $(\bowtie)$

University of California San Diego, La Jolla, CA, USA

e-mail: msoltani@ucsd.edu 